\title{
ÇOCUK VE ERGENLERDE DİKKAT EKSİKLİĞİ HIPERAKTIVITE BOZUKLUĞU VE SALDIRGANLIK
}

\section{Elif ULU ERCAN*}

\section{Öz}

DEHB çocukluk çağında \%5-7 sıklıkta görülen ve tedavi edilmediğinde psikiyatrik, akademik ve sosyal sorunlara yol açabilen nörobiyolojik bir bozukluktur. DEHB üzerinde oldukça fazla çalışma yapılmış bozukluklardan biri olmasına karşın DEHB ile oldukça yakın ilişkili olan saldırganlığın ihmal edilmiş olduğu görünmektedir. Oysa saldırganlık, DEHB'ye hem sık olarak eşlik etmekte hem de prognoz üzerinde son derece önemli bir faktör olarak görünmektedir. Bu çalışmanın amacı, DEHB ve saldırganlıkla ilişkili çalışmaları derlemektir. Çalışma kapsamında çeşitli veri tabanlarından "Dikkat Eksikliği Hiperaktivite Bozukluğu (DEHB)", "saldırganlık” anahtar kelimeleri kullanılarak ulaşılabilen çalışmalar gözden geçirilmiştir. Bazı çalışmalar DEHB ile yüksek düzeyde komorbidite gösteren Davranım Bozukluğu (DB) ve Karşıt Olma Karşı Gelme Bozukluğu'nun (KOB) DEHB'de saldırganlığın nedeni olduğunu öne sürmekle birlikte literatürdeki genel eğilim DEHB'nin KOB ve DB'den bağımsız olarak saldırganlıkla ilişkili olduğunu göstermektedir. DEHB'nin doğal gidişini aydınlatmada kritik bir önemi olan uzun izlem çalışmaları da saldırganlığın varlığının DEHB'de çok önemli bir faktör olduğunu ortaya koymaktadır. $\mathrm{Bu}$ gözden geçirme yazısında DEHB ve saldırganlık ilişkisinin nedeni, önemi, DEHB ile eşlik eden KOB ve DB olması durumunda saldırganlık şeklindeki farklılıklar ve DEHB ile birlikte saldırganlık varlığında klinik uygulama için öneriler ele alınmıştır.

Anahtar Kelimeler: Saldırganlık, DEHB, Davranım bozukluğu, Karşıt olma karşı gelme bozukluğu.

* Dr. Öğr. Üyesi, Ege Üniversitesi Eğitim Fakültesi, elif.ercan@ege.edu.tr 


\title{
Aggression and Attention Deficit and Hyperactivity Disorder in Children and Adolescents
}

\begin{abstract}
Attention deficit and hyperactive disorder (ADHD) is a common neurodevelopmental disorder in childhood and it is an important problem that affects the academic and social life of the child. Although ADHD seems to be one of the most studied disorders; aggression which is closely related to ADHD, seems to have been neglected. However, aggression, often accompany to ADHD and seems to be an extremely important factor on the prognosis. The aim of this study is to review studies on ADHD and aggression "ADHD, "Aggression" keywords were used to determine relevant studies for review. Some studies suggest that aggression is a cause of ADHD which has a high level of comorbidity with Oppositional Defiant Disorder (ODD) and Conduct Disorder (CD). But the general trend in the literature indicates that aggression is associated with ADHD independent from ODD and CD comorbidity. Follow-up studies which play a critical role in lighting the natural course of ADHD reveal that the existence of aggression is a very important factor in ADHD. In this review article, the cause and importance of the relationship between ADHD and aggression, how the presence of ODD and CD shaped differences in aggression and recommendations for clinical practice will be discussed.
\end{abstract}

Keywords: Aggression, ADHD, Conduct disorder, Oppositional defiant disorder.

\section{Giriş}

Çocukluk çağının en sık görülen bozukluklarından olan Dikkat Eksikliği Hiperaktivite Bozukluğu (DEHB) son derece önemli akademik, sosyal ve psikiyatrik sorunlara yol açabilen ve olumsuz etkileri yaşam boyu sürebilen bir bozukluktur. Bireyin, ailenin ve hatta toplumun sağlığını etkileyebilmesi nedeniyle DEHB önemli bir toplum sağlı̆̆ problemi olarak kabul edilmektedir. Yaşamın erken dönemlerinde başlayan DEHB bireyin sosyalleşmesi üzerinde de büyük etkiye sahiptir (Retz ve Rösler 2009). Amerikan Psikiyatri Birliği DEHB'nin okul çağı çocuk- 
larında \% 5-7 sıklığında olduğunu belirtmektedir (Amerikan Psikiyatri Birliği 2000); son yıllarda yapılan oldukça kapsamlı bir meta analiz çalışmasında DEHB’nin tüm dünyadaki prevalansının \% 5.29 olduğu gösterilmiştir (Polanczyk ve ark. 2014). Ülkemizde yapılan 4 yıllık uzunlamasına yapılan prevelans çalışmasında ise DEHB'nin ilköğretim çağı çocuklarında \%12 dolayında görüldüğü saptanmıştır (Ercan ve ark. 2013).

Çocukluk yaş grubunda saldırganlık ve Dikkat Eksikliği Hiperaktivite Bozukluğu (DEHB) çok iyi araştırılmış olan kavramlar olmasına karşın saldırganlık ve DEHB ilişkisi tam olarak açılığa kavuşturulamamıştır. Özellikle son yıllarda saldırganlığın tek bir kavram olarak ele alınması yerine çok yönlü olarak araştırılması saldırganlık ve DEHB ilişkisini kapsamlı bir biçimde değerlendirme gerekliliğini ortaya koymaktadır.

\section{Saldırganlık}

İnsanların ne kadar medenileştikçe o kadar saldırganlaşması oldukça şaşırtıcı bir paradokstur. Saldırgan davranışlar, insan davranışı ile ilgili teorilerin önde gelen konularındandır ve zooloji, ekonomi ve halk sağlığı gibi birçok farklı disiplinde de üzerinde çalışmalar yürütülmektedir (Tremblay 2000). Saldırganlık; evrensel, karmaşık bir gelişimsel olgudur ve üzerinde yaygın biçimde çalışılmış olmasına rağmen hala araştırmacıları şaşırtmaktadır (Harnett 1992). Çocukların oyunlarındaki kavgalardan sokak çatışmalarına ve savaşa kadar, bir insanın diğerine acı verme çabası, belki de en çok araştırılmış insan davranışıdır (Burger 2006).

Saldırganlık ruh ve bedene zarar verici, egoya karşı yaralayıcı olsa da insan olmanın gerçeği ve önemli bir parçasıdır (Geen 2001). Saldırganlığı tanımlamayla ilgili yaşanan güçlüğün sebebi bu problem davranışın çok sayıda biyolojik, kültürel, çevresel ve sosyal güçten etkilenmesidir (Eron 1987, Lindsay ve Anderson 2000). Saldırganlığı tanımlamak neredeyse psikolojinin bütün kavramlarını tanımlamaktan daha zordur (Crains 1979). 
Saldırgan davranış yaşam boyu en fazla süreklilik gösteren kişilik özelliklerinden olup, çocuklukta görülen saldırgan davranışlar yaşam boyu sürebilir ve hatta artış gösterebilir (Farrington 1991, Haapasalo ve Tremblay 1994, Loeber ve Dishion 1983, Loeber ve Hay 1997). Yapılan çalışmalar; 12 ay gibi oldukça erken bir dönemde bile çocukların az ya da çok saldırgan davranış biçimleri sergilediklerini ortaya koymaktadır (Holmberg 1980, Kagen 1988). Richman ve arkadaşları (1982), 3 yaş gibi oldukça küçük bir yaşta saldırgan davranışları olan çocukların büyük bir kısmının (\%87) 8 yaşında da saldırgan davranışları olduğunu bildirmişlerdir (Richman ve ark. 1982). Ancak bu durum sadece bir faktörün bu durumda etkisi olduğu anlamına gelmemektedir (Huesmann ve Guerra 1997).

İnsanın saldırgan davranışına ilişkin tartışmalarda temel çelişki, saldırganlığın “içgüdüsel mi?”, yoksa "sonradan kazanılan bir davranış mı?” olduğudur. Saldırganlık ve şiddet olaylarının yorumlanmasına ilişkin farklı görüşler bulunmaktadır. Bu konudaki yaklaşımlar genel olarak iki temele dayanmaktadır. Saldırganlığa ilişkin içgüdüsel ve biyolojik kuramlar saldırganlığı doğuştan gelen, insan doğasının bir parçası olarak görmektedirler. Genetik araştırmalar tek yumurta ikizlerinde saldırganlık konkordansının (her iki ikizde bir arada görülmesinin) çift yumurta ikizlerinden oldukça yüksek olduğunu ortaya koymakta ve saldırganlıkta kalıtımın rolünün $0.28-0.72$ arasında olduğunu göstermektedir (Hudziak ve ark. 2003). Önemli sayıda çalışma hem insan hem de hayvanlarda her ne kadar birçok nörokimyasal sistem işe karışsa da azalmış merkezi serotenerjik aktivitenin saldırgan davranışlarla en çok ilişkili biyolojik özellik olduğunu ortaya koymaktadır (Saubrie 1986; Yalçın, Erdoğan, 2013; Üngüren, 2015). Düşük sosyoekonomik düzey, ailesel problemler, olumsuz ebeveynlik, ebeveynlerde psikopatoloji, kalabalık aileden gelmenin saldırganlıkla en yakından ilişkili çevresel faktörler olduğu bildirilmiştir (Vaden-Kiernan ve ark. 1995). Bu durumda, saldırganlığın gelişimi ve devam etmesinde hem genetik hem de çevresel faktörlerin etkili olduğu görülmektedir (Arseneault ve ark. 2003, Dionne ve ark. 2003). 
Epigenetik, yani çevresel ve genetik etkenlerin birbiriyle etkileşimi sonucu ortaya çıkan toplam etki, çocuklarda saldırganlığın görülmesini ve gelişimle beraber ne derecede artacağ 1 ve süreceğini etkileyen temel faktördür (Loeber ve Hay 1997, Loeber ve ark. 1993).

Çocuk ve ergenlerde saldırgan davranış örüntülerinin görülme riskini artıran pek çok bireysel neden vardır. Saldırgan davranışlar gösteren çocuklarda davranışsal (hiperaktivite, dürtüsellik, dikkatsizlik), bilişsel (düşük IQ, düşük okul başarısı), sosyal / ailesel (çete üyeliği, katı çocuk yetiştirme teknikleri, çocuk istismarı, ailede çatışmalar ve düşük sosyo ekonomik statü) ve durumsal risk faktörleri (alkol, madde ve silahlara kolay ulaşabilme) beraberce saldırganlık davranışının görülmesi ve sürdürülmesine zemin hazırlamaktadır (Loeber ve Hay 1997). Görüldüğü gibi saldırgan davranışların görülmesinde tek bir etken yoktur. Ailesel özellikler saldırgan davranışların görülme sıklı̆̆ında önemli bir etkiye sahiptir. Aile Sistemleri Kuramına göre aile dinamik bir sistemdir ve ailedeki bireyin davranışları ancak ailenin diğer üyelerinin davranışları ve birbirleriyle olan etkileşimleriyle anlaşılabilmektedir (Steinglass 1987'den akt. Hetherington ve Reiss 1999).

Sosyal öğrenme kuramına göre ise (Bandura 1983,2001; Mischel 1973,1999; Mischel ve Shoda 1995) saldırganlık tepkileri, sosyal davranışların diğer karmaşık formlarındaki gibi başkalarını doğrudan ya da dolaylı biçimde gözlemleyerek kazanılmaktadır. Rutter ve arkadaşları çocukluk ruhsal bozukluklarında aile ile ilgili altı risk faktörünün belirgin şekilde etkili olduğunu vurgulamaktadır. "Rutter'ın Zorluk Faktörleri” (Rutter's Adversity Factors) olarak adlandırılan bu 6 özellik "ciddi evlilik anlaşmazlıkları, düşük sosyoekonomik düzey, kalabalık aile, baba suçluluğu, anne ruhsal bozukluğu ve üvey ebeveyn yanında yaşama"dır. Rutter'ın belirlediği olumsuz aile ve çevresel risk etmenlerinin sayısı arttıkça, çocuklarda ruhsal bozukluk görülme riskinin de arttığı bildirilmektedir (Hinshaw 1987). Biederman ve arkadaşları 1995 yılında yaptıkları çalışmada, Rutter'ın ailesel risk etmenlerinin DEHB üzerindeki etkilerini incelemişlerdir. Bu çalışmada ailesel risk etmenlerinin sayısı arttıkça, DEHB'yle birlikte görülen DB, Antisosyal 
Kişilik Bozukluğu (ASKB) gibi ruhsal sorunların eşlik etme riskinin arttığı saptanmıştır (Öktem 1993).

Literatür incelendiğinde aile faktörlerine ek olarak, saldırgan çocuklar (Coy ve ark. 2001, Vance ve ark. 2002) ve yetişkinlerde (Brownlie ve ark. 2004, Huesmann ve ark. 2002) başta sözel alanda olmak üzere bilişsel yetersizliklere rastlandığı görülmektedir. Patterson ve arkadaşları (1989) bilişsel problemlerin varlığının akademik başarısızlığa ve akranları tarafından çocukların red edilmesine yol açtı̆̆ını ve bunun da çocuğu çarpık arkadaş gruplarına ve suç işlemeye itebildiğini belirtmiştir. Bunlara ek olarak Feshbach (1970) reddeden anne-baba davranış1nın daha çok saldırgan davranışlara neden olduğunu ifade etmiştir (akt. Dodge ve Frame 1982). Sözel yönergeleri hatırlama ve eylemlerinin sonuçlarını dili kullanarak göz önüne alma, eylemlerin etkili biçimde kontrol edilmesine katkı sağlamaktadır. Akıl yürütme ve kendini sözel olarak ifade etme zorluğu yaşayan çocuklar sosyal açıdan yaşanan değişimlerin kontrolünü saldırganlığı kullanarak sağlayabilirler (Dodge 1993).

Saldırgan davranışlar çocukların psikiyatrik değerlendirmeye yönlendirildiği temel belirtilerdendir (Shaw, Owens, Giovannelli ve Winslow, 2001). Saldırganlık, genellikle çeşitli psikiyatrik bozukluklarla beraber görülmektedir Fischer, (Barkley, Smallish, Fletcher, 2002). Bu bozuklukların en önemlilerinden birisi de Dikkat Eksikliği Hiperaktivite Bozukluğu'dur (Miller ve ark. 2006).

\section{DEHB ve Saldırganlık}

DEHB olan çocukların çok önemli bir bölümü ergenlik (\%80) ve erişkinlik dönemlerinde (\%65) de DEHB tanısı almaya devam ederler (Barkley 1996, Weiss ve Hechtman 1993). Ayrıca çocukluğunda DEHB olanlar olmayanlara oranla çok daha yüksek oranda Antisosyal Kişilik Bozukluğu ve alkol-madde kullanım bozuklukları gibi psikiyatrik; kapasitenin altında okul başarısı gösterme veya okuldan atılma gibi akademik; sı1k kazaya uğrama, kazalara neden olma, sık boşanma, erken 
yaşta gebelik, düşük iş başarısı veya işsizlik gibi sosyal risklere maruz kalmaktadırlar (Barkley 2004).

Dikkat Eksikliği ve Hiperaktivite Bozukluğu saldırganlık ve antisosyal davranışlarla büyük ölçüde ilişkilidir. DEHB tanısı konulan çocuklarla okul öncesi dönemden ilköğretimin sonuna kadar yapılan boylamsal çalışmalar (4-14 yaş) bulunmaktadır. Bu çalışmaların tümünde normal kontrollerle (DEHB olmayan ve bir başka psikopatolojisi olmayan çocuklar) DEHB çocuklar arasında saldırgan davranışlar, suç işleme ve diğer antisosyal davranışlar gösterme riski açısından anlamlı fark bulunmuştur (August ve ark. 1983, Barkley ve ark. 1990, Hectman ve ark. 1984, Mannuzza ve ark. 1993, Taylor ve ark. 1996, Connor ve ark., 2010).

DEHB temel belirtilerinden olan dikkat eksikliği, saldırgan davranışları arttırabilmekte ve özellikle bu durum düşük bilişsel yeteneklerin varlığında daha da belirginleşebilmektedir (Bellanti ve ark. 2000, Schaeffer ve ark. 2003).

DEHB'nin temel belirtileri olan hiperaktivite, dürtüsellik ve dikkat eksikliği, çocukların öğrenme yetilerini olumsuz bir şekilde etkiler. Bu durumda, kendi kapasitelerinin altında başarı göstermeye veya kendi sınıf düzeylerinin gerisinde kalmaya başlarlar. Gösterdikleri olumsuz davranışlar, aldıkları cezalar, sınıf tarafindan alaylara hedef olmaları da akademik sorunlar yaratmaktadır (Yavuzer, 2002).

İlkokul birinci ve ikinci sınıftayken aşırı hareketlilik, çok konuşma ve söz dinlememe gibi belirtilere, 8-9 yaşlarından itibaren yalan söyleme, büyüklerle tartışmaya girme ve arkadaşlarıyla sık olarak kavga etme gibi davranış sorunları eklenebilmektedir. Böylece çevre tarafından "yaramaz çocuk" nitelemesi yavaş yavaş "şımarık çocuk" veya "terbiyesiz çocuk" haline gelmektedir. Arkadaşları tarafından dışlanabilen bu çocuklar okulda veya mahallede kendilerine benzer özellikler sergileyen çocuklarla birlikte gruplar oluşturabilirler. Bu gruplaşmaların ileride suça yönelik çetelere katılmada rol oynayabileceği de düşünülmesi gereken önemli bir konudur (Ercan ve Aydın 2014). 
DEHB'li çocuklar ailelerinden ve öğretmenlerinden yeterli desteği alamazlarsa, okulda uyum sorunları yaşarlarsa ve bunlara karşı önlem alınmazsa saldırgan davranışların ortaya çıkma olasılığı daha yüksek olur. Bu saldırgan davranışlar, insan ve hayvanlara karşı saldırganlık, tehdit, kurallara uymama, eşyalara zarar verme, yalan söyleme, evden ve okuldan kaçma olarak kendini gösterebilir (Le Heuzey 2005). DEHB tanısı olan çocuklarda yürütücü işlevler olarak bilinen uyanıklık, motor yanıtın durdurulması, planlama, organizasyon, öğrenme ve sözel bilginin hatırlanması gibi işlevlerde bozulma olduğu belirtilmektedir (Seidman ve ark. 2005). Son yıllarda başta Russel Barkley olmak üzere (Barkley 2010) DEHB otörleri DEHB'de yürütücü işlev bozukluklarının çekirdeğini emosyonel disregülasyonun oluşturduğu üzerinde durmaktadırlar. Emosyonel disregülasyon, çabuk sinirlenme, sık ve şiddetli öfke atakları yaşama gibi uygunsuz davranışlar olarak dışa vurulur ve bunlar saldırganlık için önemli risk faktörlerini ortaya çıkarır. Yani, DEHB ve saldırganlık farklı yapılar olmalarına karşın DEHB'nin çekirdek özellikleri olan emosyonel disregülasyon ve dürtüsellik DEHB olan çocukları saldırganl1ğa yatkın hale getirmektedir (King ve Waschbusch 2010).

Literatürde genel olarak saldırganlık proaktif ve reaktif saldırganlık şeklinde alt tiplere ayrılmaktadır. Proaktif- reaktif saldırganlık sınıflandırması DEHB ve Y1kıcı Davranış Bozuklukları kapsamında saldırganlığın çok daha iyi anlaşılmasını sağlayabileceği düşünülmektedir. Reaktif saldırganlık daha çok saldırganlığın duygusal formudur ve tehdit olarak görülen bir uyarana öfkeyle tepki verilmesini içerir. Proaktif saldırganlık ise kasti, planlı ve soğukkanlı biçimdedir ve provokasyon olmadan gerçekleşmektedir (Dodge 1991, Connor ve ark., 2010, Hinshaw 2002).

\section{DEHB ve Karşıt Olma Karşı gelme Bozukluğu-Davranım Bozukluğu Komorbiditesi}

Davranım bozukluğu (DB), karşıt olma karşı gelme bozukluğu (KOB), özgül öğrenme güçlügü sıklıkla DEHB' ye eşlik eder; bu olgularda okulda yaşanan davranışsal ve bilişsel sorunlar daha da ağırlaşabilir (Conner ve ark. 2003, Hinshaw 
2002). DEHB'nin tek başına görüldüğü durumlarda da saldırganlıkla ilişkili olduğu bilinmekle birlikte eşlik eden KOB ve DB varlığı saldırganlık görülmesi için çok daha önemli bir risk faktörüdür. DEHB, KOB ve DB'nin her birisi saldırganlık için ayrı ayrı önemli risk faktörleridir. Ancak bu bozuklukların bir arada görülmesi durumunda saldırganlık ve diğer olumsuz risk etkenleri için çok daha büyük bir risk faktörü oluştururlar. DEHB varlığında KOB görülme oranı \% 50’ler DB görülme oranı ise \% 15'ler (MTA 1999) gibi çok yüksek oranlardadır. Benzer biçimde KOB olanların neredeyse \% 70-80'inde DB olanların ise \%90'ında eşlik eden DEHB bulunduğu belirtilmektedir (Green ve ark. 2008). DEHB olan olgularda eşlik eden KOB ve DB olması durumunda sadece DEHB olan olgulara göre daha yüksek saldırganlık görülme riski ve olumsuz prognoz söz konusu olurken, benzer biçimde KOB ve DB olan çocuklarda da DEHB komorbiditesi sadece KOB ve DB'ye göre daha olumsuz gidişe neden olabilmektedir.

DEHB ile birlikte KOB ve DB görülmesi durumunda sadece saldırganlık görülme sıklığı değil saldırganlık şeklinde de değişiklikler görülmektedir. DEHB'de emosyonel disregülasyon ve dürtüsellik temel sorun alanları olduğundan, DEHB daha çok reaktif saldırganlıkla yakın ilişkilidir. Dodge ve arkadaşları (Dodge ve ark. 1997), yüksek düzeyde reaktif saldırganlık gösteren çocukların aynı zamanda daha fazla dikkat eksikliği ve dürtüsellik gösterdiklerini bildirmişlerdir. Benzer biçimde, sadece DEHB olan, DEHB ve KOB olan ve DEHB ile DB olan olguların saldırganlık özellikleri bakımından karşılaştıııldığı bir çalışmada da (Waschbusch ve ark. 2002) sadece DEHB olan olgularda reaktif saldırganlığın en sık görüldüğü belirlenmiştir. DEHB ve KOB olan olguların ise düşük provokasyonla saldırgan tepkiler gösterebildiği saptanmıştır. Yine sadece DEHB olan olgulara göre DEHB ve KOB ya da DB olan olguların provokasyon karşısında daha uzun süre kin tuttukları ve saldırgan davranışlarını sürdürdükleri gözlenmiştir. Şiddetli düzeyde saldırganlık, saldırı başlatma ve alet-silah kullanarak saldırganlık en fazla DEHB ve DB olan olgularda görülmektedir. DEHB ve KOB olan olgular ise saldırganlık özellikleri bakımından sadece DEHB olan olgularla DEHB ve DB olan 
olguların ortasında bir yer almaktadırlar. DEHB ve KOB olan olguların saldırgan davranışlarına ilişkin en önemli özelliklerden birisi de bu grubun en fazla sözel saldırganlığı seçmesidir (Ulu, 2018).

\section{DEHB'de Saldırganlığın Ele Alınması}

DEHB'nin temel belirtileri içerisinde yer almasa da saldırganlık DEHB olan çocuklarda üzerinde durulması gereken oldukça önemli bir sorundur. DEHB olan olgularda saldırganlık belirtileri hiç gözlenmeden önlem alınarak DEHB'nin tedavi edilmesi ve böylece klinik tablonun şiddetlenmeden, sadece DEHB belirtilerine sınırlıyken tedavi edilmesi en doğru yoldur. Son yillarda oldukça kabul gören "Tedavi edilmeyen DEHB bileşik tip DEHB ve KOB için; benzer biçimde tedavi edilmeyen DEHB ve KOB de DEHB ve DB için oldukça önemli bir risk faktörü oluşturmaktadır." hipotezi de DEHB saldırganlık ilişkisini ve tedavi edilmeyen DEHB'nin olumsuz gidiş göstereceği bulgularını desteklemektedir (Connor ve ark., 2010; Holmes, Slaughter ve Kashani, 2001). DEHB'de saldırganlık genellikle reaktif doğada veya sözel saldırganlık şeklinde görülmekle birlikte ileriki yıllarda saldırganlık şekli ve/veya şiddetinde de artış olabileceği göz önüne alınmalıdır. Diğer yandan saldırganlık bulunması durumunda DEHB olgularda etkin ilaç tedavisinin yanı sıra başta ebeveyn eğitimi olmak üzere bütüncül bir tedavi programının uygulanması gereklidir.

\section{Sonuç}

Dünya Sağlık Örgütü’ ne (WHO) göre şiddet tüm dünyada belli başlı genel sağlı problemlerinden biridir ve Örgüt her yıl kişilerarası şiddet nedeniyle dünya genelinde yaklaşı 1.6 milyon insanın hayatını kaybettiğini bildirmiştir (Krug ve ark. 2002).

Ülkemizdeki durum incelendiğinde ise Milli Eğitim Bakanlığı Özel Eğitim Rehberlik ve Danışma Hizmetleri Genel Müdürlüğü tarafindan yayınlanan 2006/26 numaralı "Okullarda şiddetin Önlenmesi” konulu genelge dikkati çekmektedir. 
Genelgede şöyle denmektedir: "Son günlerde Bakanlığımıza intikal eden bilgilerden, görsel ve yazılı medyada yer alan haberlerden özellikle okullarımızda şiddet, saldırganlık, zorbalık gibi olayların arttığı anlaşılmaktadır. Öğrencilerin güven ortamı içinde eğitim kurumlarına devam edebilmelerini sağlamak ve eğitim sisteminden istenilen başarıyı elde edebilmek amacıyla koruyucu ve önleyici çalışmaların önemi artmaktadır."

DEHB çocuklarda saldırganlık ile en yakından ilişkili bozukluklardan olduğundan, DEHB olan olgularda saldırgan ve saldırganlık için risk etkenleri oldukça ayrıntılı bir biçimde değerlendirilmeli ve erken önlem alınması son derece önemli bir olgudur. Okullarımızda psikolojik danışma ve rehberlik servislerinde saldırganlığı azaltmaya yönelik müdahale programları geliştirilmesi ve bu programlara aileleri de dâhil etmek daha da etkili bir yardım sunulmasına katkı sağlayabilir.

\section{Kaynakça}

Amerikan Psikiyatri Birliği. (2000). DSM-IV-TR tanı ölçütleri: başvuru elkitabı (2. baskı). (Çev. Ertuğrul Köroğlu). Ankara: Hekimler Yayın Birliği.

Amerikan Psikiyatri Birliği. (2013). DSM - 5: Ruhsal bozuklukların tanısal ve sayımsal elkitabı. (Çev. Ertuğrul Köroğlu). Ankara: Hekimler Yayın Birliği.

Arseneault L, Moffit TE, Caspi A ve ark. (2003). Strong genetic effects on cross-situational antisocial teachers, examiner-observers, and twins' self-reports. J Child Psychol Psychiatry, 44, 832-848.

August, G. J., Stewart, M. A., \& Holmes, C. S. (1983). A four-year follow-up of hyperactive boys with and without conduct disorder. The British Journal of Psychiatry, 143(2), 192-198.

Bandura A (2001) Social cognitive theory: an agentic perspective. Ann Rev Psychol, 52, 126.

Bandura A (1983). Psychological mechanisms of aggression. aggression: theoretical and empirical reviews içinde rs geen ve e donnerstein. (ed) Academic Press, New York, 11-40. 
Bandura A, Walters, R. H. (1963). Social learning and personality development. Holt: Rinehart \& Winston.

Barkley RA (2010) Deficient emotional selfregulation: a core component of attention deficit/hyperactivity disorder. JARD, 1, 5-37.

Barkley, R. A., DuPaul, G. J., \& McMurray, M. B. (1990). Comprehensive evaluation of attention deficit disorder with and without hyperactivity as defined by research criteria. Journal of consulting and clinical psychology, 58 (6), 775.

Baron RA, Richardson DR (1994). Human aggression (2. ed.). New York: Plenum.

Berkowitz L (1993). Pain and aggression:some findings and implications. Motiv Emot, 17, 277-93.

Burger JM (2006) Kişilik. (Çev. İD Sarığlu). İstanbul: Kaknüs Yayınları.

Bushman BJ, Anderson CA (2001). Is it time to pull the plug on the hostile versus instrumental aggression dichotomy? Psychol Rev, 108, 273-79.

Connor, D. F., Edwards, G., Fletcher, K. E., Baird, J., Barkley, R. A., \& Steingard, R. J. (2003). Correlates of comorbid psychopathology in children with ADHD. Journal of the American Academy of Child \& Adolescent Psychiatry, 42 (2), 193-200.

Connor, DF., Chartier, G., Preen, EC., Kaplan, RF. (2010). Impulsive aggression in attention-deficit/hyperactivity disorder: symptom severity, co-morbidity, and attentiondeficit/hyperactivity disorder subtype. Journal of Child and Adolescent Psychopharmacology, 20 (2) 119-126.

Coy K, Speltz ML, DeKlyen M ve ark. (2001). Social-cognitive processes in preschool boys with and without oppositional defiant disorder. J Abnorm Child Psychol, 29, 107-119.

Crains R (1979). Social development: The origins and plasticity and interchanges. San Francisco: Freeman.

Dionne G, Tremblay RE, Boivin M, ve ark. (2003). Physical aggression and expressive vocabulary in 19 month old twins. Dev Psychol, 39, 261-273.

Dodge KA, Lochman JE, Harnish JD ve ark. (1997). Reactive and proactive aggression in school children and psychiatrically impaired chronically assaultive youth. $J A b$ norm Psychol, 106, 37-51.

Dodge KA (1993). Social-cognitive mechanisms in the development of conduct disorder and depression. Annu Rev Psychol, 44, 559-84. 
Dodge KA, Frame CL (1982). Social cognitive biases and deficits in aggressive boys. Child Dev, 53, 620-635.

Ercan ES, Aydın C (2014). Anne-baba ve eğitimciler için dikkat eksikliği hiperaktivite bozukluğu. Pupa Yayınevi.

Ercan ES, Kandulu R, Uslu E ve ark. (2013). Prevalence and diagnostic stability of ADHD and ODD in Turkish children: a 4-year longitudinal study. CAPMH, 7, 30.

Eron L (1987) The development of aggressive behavior from the perspective of a developing behaviorism. Am Psychol, 42, 435-442.

Farrington DP (1991) Antisocial personality from childhood to adulthood. The Psychologist, 389-394.

Fischer, M., Barkley, R. A., Smallish, L., \& Fletcher, K. (2002). Young adult follow-up of hyperactive children: self-reported psychiatric disorders, comorbidity, and the role of childhood conduct problems and teen CD. Journal of abnormal child psycho$\log y, 30(5), 463-475$.

Geen G (2001) Human aggression (2. Ed.). Philadelphia, USA: Open University Press.

Haapasalo J, Tremblay RE (1994). Physically aggressive boys from ages 6 to 12: Family background parenting behavior, and prediction of delinquency. J Consult Clin Psychol, 62, 1044-1052.

Halperin JM, Newcorn JH, Kopstein I ve ark. (1997). Serotonin, aggression, and parental psychopathology in children with attention deficit hyperactivity disorder. $J \mathrm{Am}$ Acad Child Adolesc Psychiatry, 36,1391-1398.

Hechtman, L., Weiss, G., \& Perlman, T. (1984). Hyperactives as young adults: Past and current substance abuse and antisocial behavior. American Journal of Orthopsychiatry, 54(3), 415.

Harnett NE (1992). Aggression in psychiatrically disordered children and adolescent. Yayınlanmış doktora tezi, University of Maryland.

Harpaz-Rotem I, Rosenheck RA (2004). Changes in outpatient psychiatric diagnosis in privately insured children and adolescents from 1995 to 2000. Child Psychiatry Hum Dev, 34, 329-40.

Hinshaw SP (1987). On the distinction between attentional deficits/hyperactivity and conduct problems/aggression in child psychopathology. Psychol Bull, 101, 443-463. 
Hinshaw, S. P. (2002). Preadolescent girls with attention-deficit/hyperactivity disorder: I. Background characteristics, comorbidity, cognitive and social functioning, and parenting practices. Journal of consulting and clinical psychology, 70 (5), 1086.

Holmberg M (1980). The development of social interchange patterns from 12-42 months. Child Developmen, 51, 448-456.

Holmes, SE., Slaughter, JR., Kashani, J. (2001). Risk factors in childhood that lead to the development of conduct disorder and antisocial personality disorder. 31, 183-193

Hudziak JJ, Van Beijsterveldt CE, Bartels M ve ark. (2003). Individual differences in aggression:genetic analyses by age, gender, and informant in 3-, 7-, and 10-yearold Dutch twins. Behav Genet, 33, 575-589.

Huesmann LR, Guerra NG (1997). Children's normative beliefs about aggression and aggressive behavior. J Pers Soc Psychol. 72, 408-419.

Kagen J (1988) Temperamental contributions to social behavior. Am Psychol. 44, 668-674.

Kim JE, Hetherington EM, Reiss D (1999). Associations among family relationships, antisocial peers, and adolescents' externalizing behaviors: Gender and family type differences. Child Dev., 70, 1209-1230.

King S, Waschbusch DA (2010). Aggression in children with attention deficit hyperactivity disorder. Expert Rev Neurother, 10, 1581-1594.

Köknel Ö (1999). Bireysel ve toplumsal şiddet. İstanbul: Altın Kitaplar.

Krug GE, Dahlberg LL, Mercy AJ ve ark. (2002). World Report on Violence and Health. Geneva: WHO publications.

Lindsay JJ, Anderson CA (2000). From antecedent conditions to violent actions: a general affective aggression model. Pers Soc Psychol Bull, 26, 533-547.

Loeber R, Hay D (1997). Key issues in the development of aggression and violence from childhood to early adulthood. Ann Rev Psychol, 48, 371-410.

Loeber R, Wung P, Keenan K ve ark. (1993). Developmental pathways in disruptive child behavior. Dev Psychopathol, 5, 103-133.

Loeber R, Dishion T (1983). Early predictors of male delinquency: A review. Psychol Bull, 94, 68-99.

Mannuzza, S., Klein, R. G., Bessler, A., Malloy, P., \& LaPadula, M. (1993). Adult outcome of hyperactive boys: Educational achievement, occupational rank, and psychiatric status. Archives of General Psychiatry, 50 (7), 565-576. 
Miller C, Miller SR, Trampush J ve ark. (2006). Family and cognitive factors: modeling risk for aggression in children with ADHD. J Am Acad Child Adolesc Psychiatry 3, 355-363.

Mischel W (1999). Personality coherence and dispositions in a cognitive-affective personality (CAPS) approach içinde, The Coherence of Personality: Social-Cognitive Bases of Consistency, Variability, and Organization, D Cervone ve Y Shoda (ed.) New York: Guilford, s. 37-60.

Mischel W, Shoda Y (1995). A cognitive affective system theory of personality: reconceptualizing situations, dispositions, dynamics, and invariance in personality structure. Psychol Rev, 102, 246-68.

Mischel W (1973). Toward a cognitive social learning reconceptualization of personality. Psychol Rev, 80, 252-83.

Öktem F, Sonuvar B (1993). Dikkat eksikliği tanısı alan çocukların özellikleri. Türk Psikiyatri Dergisi, 4, 267-272.

Patterson GR, DeBaryshe BD, Ramsey E (1989). A developmental perspective on antisocial behavior. Am Psychol, 44, 329-335.

Polanczyk, GV., Willcutt EG., Salum, GA., Kieling C., Rohde, LA. (2014). ADHD prevalence estimates across three decades: an updated systematic review and metaregression analysis. International Journal of Epidemiology, 43 (2), 434-442.

Ramirez JM, Andreu JM (2006). Aggression, and some related psychological constructs (anger, hostility, and impulsivity)-Some comments from a research project. Neurosci Biobehav Rev. 3, 276-291.

Retz W, Rösler M (2009). The relation of ADHD and violent aggression: What can we learn from epidemiological and genetic studies? Int J Law Psychiatry, 32, 235-43.

Richman N, Stevenson J, Graham PJ (1982). Pre-school to school: A behavioral study. London: Academic Press.

Seidman LJ, Valera EM, Makris N (2005). Structural brain imaging of attentiondeficit/hyperactivity disorder. Biol Psychiatry, 57, 1263-1272.

Shaw, D. S., Owens, E. B., Giovannelli, J., \& Winslow, E. B. (2001). Infant and toddler pathways leading to early externalizing disorders. Journal of the American Academy of Child \& Adolescent Psychiatry, 40 (1), 36-43. 
Soubrie P (1986). Reconciling the role of central serotonin neurons in human and animal behavior. Behav Brain Sci, 9, 319-364.

Tahiroğlu YA, Avcı A, Fırat S ve ark. (2005). Dikkat eksikliği hiperaktivite bozukluğu: alt tipleri. Anadolu Psikiyatri Dergisi, 6, 5-10.

Taylor, E., Chadwick, O., Heptinstall, E., \& Danckaerts, M. (1996). Hyperactivity and conduct problems as risk factors for adolescent development. Journal of the American Academy of Child \& Adolescent Psychiatry, 35 (9), 1213-1226.

Tremblay R (2000). The development of aggressive behaviour during childhood:What have we learned in the past century? Int J Behav Dev, 24, 129-141.

Ulu, E. (2018). Saldırganlık tüm DEHB'li erkek çocuklarında aynı biçimde midir? Kastamonu Eğitim Dergisi. Baskıda.

Üngüren, E. (2015). Beynin nöroanatomik ve nörokimyasal yapısının kişilik ve davranış üzerindeki etkisi. Uluslararası Alanya İşletme Fakültesi Dergisi, 7 (1), 193-219.

Vaden-Kiernan N, Ialongo NS, Pearson J ve ark. (1995). Household family structure and children's aggressive behavior: A longitudinal study of urban elementary school children. J Abnorm Child Psychol, 23, 553-568.

Vance JE, Bowen NK, Fernandez G ve ark. (2002) Risk and protective factors as predictors of outcome in adolescents with psychiatric disorder and aggression. J Am Acad Child Adolesc Psychiatry, 41, 36-43.

Yavuzer H (2002). Eğitim ve gelişim özellikleriyle okul çağı çocuğu. Ankara: Remzi Kitabevi.

Yalçın, Ö., \& Erdoğan, A. (2013). Siddet ve agresyonun nörobiyolojik, psikososyal ve çevresel nedenleri/neurobiological, psychosocial and enviromental causes of violence and agression. Psikiyatride Guncel Yaklasimlar, 5 (4), 388.

Waschbusch DA, Pelham WE, Jennings JR ve ark. (2002). Reactive aggression in boys with disruptive behavior disorders: behavior, physiology, and affect. J Abnorm Child Psychol, 30, 641-656. 